\title{
QUÉ NOS ENSEÑA EL CAPITAL CULTURAL PARA PENSAR EL CAPITAL ERÓTICO
}

\author{
José Luis Moreno Pestaña*
}

RESUMEN: En el presente artículo recupero ciertos análisis sobre el capital cultural. Con ellos me interrogo acerca de su utilidad para analizar el capital erótico. El trabajo se centra, fundamentalmente, en dos problemas. El primero es la débil institucionalización del capital erótico, diferencia de peso respecto del capital cultural. La segunda en cómo podemos analizar las desigualdades corporales atendiendo a ciertos problemas de la investigación sociológica y filosófica sobre el capital cultural. Como conclusión se justifica que el capital erótico puede considerarse un tipo de capital cultural y se definen las condiciones por las que los sujetos pueden enfrentarse a formas de dominación vinculadas al capital erótico.

Palabras-clave: Capital cultural; Capital erótico; Desigualdades culturales; Desigualdades corporales; Sociología francesa.

\section{WHAT WE CAN LEARN FROM THE CULTURAL CAPITAL TO REFLECT UPON THE EROTIC CAPITAL}

ABSTRACT: In this article some analyses on cultural capital have been retrieved. Based on them, we interrogated about their usefulness for analyzing erotic capital. The work focuses primarily on two issues. The first one is the weak institutionalization of erotic capital, when compared to the weight given to cultural capital. The second one is related to how we can analyze the body inequalities in response to certain problems regarding the sociological and philosophical research on cultural capital. We conclude by asserting that erotic capital can be considered a kind of cultural capital. The article also defines the conditions under which individuals can fight against forms of domination linked to erotic capital.

Keywords: Cultural capital; Erotic capital; Cultural inequalities; Body inequalities; French sociology.

\footnotetext{
* Universidad de Cádiz, Facultad de Filosofía y Letras, Cádiz, Espanha. E-mail de contato: joseluis.moreno@uca.es
} 


\title{
CE QUE NOUS APPREND LE CAPITAL CULTUREL POUR PENSER LE CAPITAL ÉROTIQUE
}

\begin{abstract}
RÉSUMÉ: Dans cet article je récupère certaines analyses sur le capital culturel pour m'interroger sur leur utilité pour comprendre le concept de capital érotique. Le texte se centre, exactement, dans deux problèmes. Le premier est la faible institutionnalisation du capital érotique, différence important par rapport au capital culturel. La seconde est comment analyser les inégalités autour du capital érotique, question pour laquelle j'utilise enquêtes philosophiques et sociologiques sur le capital culturel. Pour conclure on justifie que le capital érotique peut être considéré un type de capital culturel et on définît des formes possibles d'antagonisme autour de la domination du capital érotique.
\end{abstract}

Mots-clés: Capital culturel; Capital érotique; Inégalités culturelles; Inégalités corporelles; Sociologie française.

\section{Capital erótico como capital cultural ${ }^{1}$}

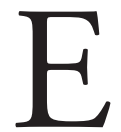

n otro trabajo (MORENO PESTAÑA; BRUQUETAS CALLEJO, 2015) defendimos que el concepto de capital erótico, acuñado por Catherine Hakim (2012), se comprende mejor como un tipo de capital cultural. La idea puede rastrearse entre los teóricos de éste. Passeron (1982, p. 576578) notaba cómo la presentación de los individuos mejora los rendimientos de los diplomas. Citando con aprobación a Pierre Bourdieu (con quien había dejado de trabajar), señalaba una paradoja de los recursos simbólicos: funcionan como capital, con mayor eficacia, cuando el detentador de credenciales los siente una propiedad merecida e incorpora sus recursos culturales en su mímica, su entonación, su silueta, su porte. La incorporación del capital cultural es uno de los rasgos de su valor. No solo porque los conocimientos deben convertirse en competencias efectivas (el cirujano conoce el uso del bisturí, el crítico de arte el significado del cuadro), sino porque cada cuerpo debe compaginarse, al máximo, con el ideal social atribuido al título. Un médico demasiado gordo desentona en una profesión que estigmatiza "científicamente" el sobrepeso: su mensaje se volvería incoherente.

El capital erótico valoriza los atributos estéticos de los individuos. Hakim (2012) sostenía que resultaba irreductible al capital económico, al cultural o al social. Sin embargo, la morfología física, la vestimenta, el don de gentes, la buena forma física, el atractivo o incluso la habilidad sexual pueden adquirirse y modularse: posteriormente cabe invertirlos en diferentes mercados. El capital cultural se expresa, según Bourdieu (1979), en tres estados: incorporado, institucionalizado y objetivado. La incorporación sirve para mostrar la gracia, en 
la que se gesta el atractivo y el don de gentes. Pero esa gracia funciona mejor cuando se sabe qué ropa ponerse, cómo moldear el cuerpo, cuál es el valor de la delgadez o la corpulencia: distintos ejercicios, consejos, cosméticos, funcionando como capital cultural objetivado, deben ser elegidos, analizados e integrados. Así pasan de ser ofertas en un mercado de productos objetivados y se convierten en estilo incorporado. En fin, una panoplia cada vez mayor de títulos (capital cultural institucionalizado) confirman las competencias estéticas de los individuos: desde la cirugía estética a las peluquerías, pasando por la endocrinología.

Pero esta referencia, rápidamente, despierta insatisfacción. La cirugía o la endocrinología son especialidades sanitarias que solo colateralmente persiguen la belleza. Tampoco resulta fácil reducir la peluquería al embellecimiento: también ofrece consejos para la conservación del cabello. La analogía con el capital cultural se atranca en un punto: el capital erótico produce escaso capital cultural institucionalizado, lo contrario del capital cultural que suele tener, en general, correspondencia en los sistemas de enseñanza.

Considerar que la cultura corporal puede funcionar como un capital es una analogía que requiere justificarse. Los hallazgos conceptuales en ciencias sociales surgen de procesos específicos de reflexión sobre la producción y tratamiento de datos. Dado que dos contextos de investigación nunca son idénticos, cabe preguntarse con qué derecho lo que resulta apropiado en un contexto (la identificación de la cultura con un capital, caso del capital cultural) puede serlo en otro: en este caso, la identificación de los recursos corporales con un capital cultural. Cabe preguntarse: el cuerpo es un capital, ¿en qué sentido? Y ¿qué en él se parece y qué no al capital cultural, tal y como fue definido por cierta tradición sociológica? Las analogías pueden ser pertinentes en unos puntos e inadecuadas en otros. La argumentación en ciencias sociales no gana nada (salvo el prestigio de la afiliación a una corriente prestigiosa) aplicando términos sin cuestionarse qué se asemeja entre dos contextos de análisis, descripción y explicación: aquel en que surgieron y aquel que pretenden esclarecer. (PASSERON, 2007, p. 13)

\section{Les Héritiers en una secuencia}

Para acometer esta tarea voy a centrarme en las dos primeras publicaciones de Bourdieu y Passeron: Les Héritiers y La Reproduction, la primera de 1964 y la segunda de 1970. Seleccionaré aportaciones de ambas obras que permiten analizar los procesos de valorización corporal y aumentar, por tanto, no solo claridad conceptual sino también tareas de investigación. Al hilo de la argumentación utilizaré, como hasta ahora, otras referencias de los dos autores, publicadas ya en solitario. 
Ambas obras se producen dentro de una red de debate sobre el papel de la escuela. Escogeré la que vincula a Bourdieu y Passeron con el grupo de Louis Althusser, en cuyo seminario participaban y del cual saldrían dos trabajos, para el asunto que nos ocupa, importantes. El primero es el artículo Idéologie et appareils idéologiques d'État, publicado por Althusser en 1970 (en la revista La pensée, $\left.n^{\circ} 151\right)$. Hoy, bajo el título Sur la reproduction, disponemos del trabajo completo del que se extrajo ese artículo. El filósofo francés preparaba un libro sobre la escuela, de lo que deja trazas en el texto. (ALTHUSSER, 1995, p. 114) También aparece el vínculo con el trabajo de Bourdieu y Passeron. (ALTHUSSER, 1995, p. 62) Un libro, este sí publicado, y directamente conectado con Althusser, fue L'École capitaliste en France, de los sociólogos Baudelot y Establet. En él las referencias a Bourdieu y Passeron son constantes. ${ }^{2}$

La exposición se articulará en dos grandes partes. La primera explorará la rareza de uno de los tres estados del capital cultural, el institucionalizado. La segunda analizará las razones de la distribución desigual del capital corporal legítimo.

\section{Parte}

\section{Un capital difícil de institucionalizar}

\subsection{La producción informal del capital corporal}

Una de las grandes aportaciones de Les Héritiers fue detectar el valor escolar de un capital cultural producido al margen del sistema educativo. Efectivamente, la escuela (en realidad los estudiantes parisinos de Letras, tipo ideal utilizado por Bourdieu y Passeron) privilegiaba recursos culturales transmitidos por la familia y por las redes sociales de los alumnos privilegiados. Estos pueden así rechazar ostentosamente los modelos explícitos de adquisición cultural. El heredero hace valer su cultura prescindiendo del aprendizaje escolar rutinario, símbolo del esfuerzo, del conformismo con la norma escolar y, a la postre, denostado como sinónimo de falta de brillantez.

Un fuerte trabajo de disimulación (a veces consciente, en general inconsciente) ignora las condiciones sociales desde las que el estudiante culto (el "heredero") exhibe sus acrobacias intelectuales. En primer lugar, ya se ha dicho, ese capital, producido y acumulado al margen de la institución, obedece a las normas del medio intelectual - del que tales herederos se encuentran cercanos socialmente. En segundo lugar, los profesores admiran, sobre todo, la cultura brillante y premian las conductas osadas de los privilegiados. Riesgo hay poco: aunque los profesores no expliquen con claridad su temario, los discípulos bur- 
gueses, al recibir una enseñanza extraescolar constante, asimilarán aquello que no se les enseña. (BOURDIEU; PASSERON, 2003, p. 78) Los autores, al final de la obra, proponen una pedagogía racional: la escuela debe exigir solo lo que ofrece. Además, debe compensar, ampliando y renovando la herencia pedagógica, las carencias culturales de los estudiantes de origen modesto. El objetivo es evaluar los costes relativos de cada acción educativa y, por supuesto, de la recepción de los públicos. No se trata, en este último punto, de subir la mano ante quien, sin recursos culturales previos, se esfuerza, sino de proporcionar todo lo necesario para que el alumno adquiera, gracias a la enseńanza explícita, lo que el heredero aprende por ósmosis:

La enseñanza realmente democrática es aquella que se propone como fin incondicional permitir al mayor número de individuos el adquirir en el menor tiempo posible, lo más completa y perfectamente posible, el mayor número posible de las aptitudes que conforman la cultural educacional en un momento dado [...]. (BOURDIEU; PASSERON, 2003)

Para lo cual, no basta con aumentar la dotación económica de los desfavorecidos, sino que se requiere "[...] una pedagogía racional que se lleve a la práctica para neutralizar, desde el jardín de infancia hasta la universidad, la acción de los factores sociales de desigualdad cultural [...]". (BOURDIEU; PASSERON, 2003)

Passeron (2007, p. 10-12) recuerda cómo un contendiente fundamental de la noción del capital cultural era el recurso a explicaciones genéticas de la desigualdad en general y educativa en particular. Raymond Aron temía que, de eliminarse las desigualdades culturales, los fracasados verían a las claras que lo suyo era genético. Mejor dejarles en la duda de si se debía a sus hándicaps sociales. Solo un ejemplo entre varios, en un momento en que las investigaciones sobre el fracaso escolar contaban aún con la inteligibilidad genética. El Oficio de sociólogo, con su exigencia de explicar "lo social por lo social", codificó, como principio compartido de cualquier sociología, el rechazo del naturalismo.

Como el capital cultural de los herederos, el capital erótico se encuentra débilmente institucionalizado. No parece difícil encontrar correspondencia entre los libros de una biblioteca y los productos de belleza - ejemplo de capital cultural objetivado. Resulta fácil vincular el estilo desenvuelto de la cultura de los herederos con el atractivo físico, aparentemente nacido del garbo natural de los sujetos. No existe, sin embargo, equivalencia entre el sistema escolar y la distribución de credenciales en los cursos privados o módulos, relativamente marginales, del sistema de enseñanza consagrados al capital erótico. La analogía entre el capital erótico y el cultural chirría en este punto. 


\subsection{La resistencia al capital corporal: el caso griego}

Convertir el cuerpo en capital, significa encarnar las diferencias sociales. Todo cuerpo comunica por su morfología, por la ropa que luce. Cuando hablamos de encarnación suponemos que a una y a otra le atribuimos una identidad y que ésta se encuentra socialmente valorada o denigrada, en suma, que proporciona cierto poder al individuo: poder para ser admirado, poder para conseguir ciertos objetivos. ${ }^{3}$ Ambas formas de poder no tienen pueden no andar siempre de la mano: la admiración que se logra puede impedir lograr ciertos objetivos.

Todo indica que dicho problema apareció muy pronto en la historia. Testimonios existen de Grecia en los siglos V y VI ANE. En el panfleto antidemocrático del Viejo Oligarca, se encuentra una queja amarga de cómo, en Atenas, los cuerpos no incorporan las marcas de las diferencias sociales: nadie sabe, paseándose por la ciudad, si estamos ante esclavos, metecos o libres. De ese modo, no puede exigírseles deferencia. (OSBORNE, 2011, p. 24) Confrontarnos a una formación social lejana, ayuda a comprender lo arbitrario de nuestros juegos de distinción corporal.

Comenzaré por la última de las dimensiones del cuerpo a las que me referí: la identidad (las otras dos, recuerdo, eran el cuerpo y el vestido). Disponemos, sobre el valor del cuerpo para la identidad, de un ramillete de críticas procedentes de medios intelectuales. Todas ellas vinculan el cultivo atlético del cuerpo con la inutilidad política. Sócrates, por ejemplo, en La República (404a), retrataba así las costumbres de los atletas: "Se trata de un régimen [de vida] apto para producir somnolencia y hacer la salud precaria. ¿No has observado que estos atletas se pasan la vida durmiendo $y$, a poco que se aparten de las normas que les han fijado sufren grandes y violentas enfermedades?”. Jenófanes de Colofón se reclamaba, en cuanto versado en asuntos públicos, más útil para la ciudad que cualquier héroe de las Olimpiadas. Eurípides, en un fragmento de un drama satírico, consideraba a los atletas el peor de los males de Grecia. Pendientes de su régimen, promueven una vida obtusa: "Sería mejor coronar a los hombres de bien y apreciar a aquellos que saben actuar del mejor modo para la ciudad y apartar de ella los males con sus palabras [...]”. (ROMILLY, 1997, p. 53-54) La misma crítica se encuentra en Isócrates. Utilizando nuestros términos: el capital atlético se encontraba en conflicto con el capital cultural: específicamente, con aquel necesario para la vida política activa.

Recuperemos la primera dimensión, la morfología física en dos de sus dimensiones: la belleza física y la capacidad de enmendar el cuerpo. Respecto a lo primero, Osborne (2011, p. 33-36), leyendo dos diálogos de Platón (Cármides y Lisis), muestra la inexistencia de un exclusivo criterio de belleza física. La belleza de los cuerpos depende del efecto producido en los demás. Para lo cual en nada ayuda el entrenamiento atlético. ${ }^{4}$ Más concretamente, Platón exige búsqueda de 
proporcionalidad entre cuerpo y alma e, igual que, como se acaba de comprobar, critica a los atletas, lo hace también con los glotones, incapaces de consagrarse al trabajo espiritual por su dependencia de los placeres del vientre. Platón, sin embargo, no conecta glotonería y gordura. Un gordo puede permanecer equilibrado internamente, y, por ende, no encarnar degradación moral alguna: cuerpo y alma se combinan en él perfectamente. (HILL, 2011, p. 52-53) El atletismo, por lo demás, conduce a menudo a comer en exceso y a la obesidad ya que el cuerpo tiene mucho de ingobernable.

La belleza morfológica, por tanto, no depende de un exclusivo patrón. Además, y esto es muy importante, el cuerpo no puede acumularse como capital porque no se encuentra pedagógicamente disponible. El desconocimiento de la circulación de la sangre impedía que la medicina hipocrática conectase ejercicio y musculatura. Por tanto, la constitución física era un dato natural ante el que poco podía hacerse. (OSBORNE, 2011, p. 49-50) Con un cuerpo atlético se nacía; si se tenía, podía emplearse en el deporte, aunque existen representaciones de atletas barrigudos. Belleza plural, desconexión entre salud y deporte e indisponibilidad pedagógica del cuerpo. Sin esos tres componentes la empresa de encarnar las desigualdades sociales se encuentra severamente limitada.

Pero, ¿y qué sucede con la ropa? Osborne (2011, p. 151-152) recuerda la impresionante capacidad técnica de los escultores para captar matices en los atuendos - la caballería tracia del Partenón se impone como ejemplo. Pese a lo cual, los escultores no diferencian, de manera sistemática, la apariencia según el estatus social (por ejemplo, ser o no un ciudadano) y etnicidad. Atenas, nos recuerda, fue una sociedad compleja donde se utilizaban botas de origen tracio, faldas lacedemonias e incluso motivos persas, sin que nada de ello determinase una específica categoría social. Las estatuas persiguen más mostrar el alma del individuo, su personalidad. Su vestimenta no nutre un relato de privilegio y jerarquía.

Ni la morfología, ni la ropa permitían definir, en la vida cotidiana, la identidad social del individuo. No lo testimonia únicamente el enfado del Viejo Oligarca. Sirva como ejemplo en Osborne (2011, p. 112-113), el análisis de la estatua de Harmodio y Aristogitón, los amantes tiranicidas, símbolo de la libertad y ubicado en un lugar prominente del Ágora. El conjunto nos muestra a Harmodio, el joven deseado por Hiparco y a su amante, más provecto: el escultor sabe relatarnos la historia y decirnos quién despertó la libido invasiva del tirano. Pero el la escultura no informa de algo y ese silencio resulta fundamental. Herodoto lo refiere: procedentes de Eritrea y de origen fenicio, ninguno de los dos era ciudadano de pleno derecho; por su procedencia y, en el caso de Harmodio, además, se encontraba el obstáculo de su juventud. El artista no consideró necesario reflejarlo y prefirió dejar desnudos a los amantes. Todo ello en un mundo donde las marcas étnicas o la edad podían utilizarse para demostrar importantes diferencias políticas en la vida cotidiana: entre ciudadano y meteco o entre hombre adulto y ciudadano 
y joven en formación. El arte griego trabaja con modelos morales, más que sociales y, como concluye Osborne (2011, p. 76), de nada sirve estudiarlo persiguiendo las referencias a la distinción social. La sociedad griega, concluye, no entra en el modelo de Pierre Bourdieu. Sencillamente, las diferencias sociales existían pero no se encarnaban. La belleza plural, la solidez de la morfología, difícil de transformar, la desconexión de la salud moral y corporal con la morfología, la hibridación cultural en abalorios y, con todo ello, la crítica radical de parte del mundo intelectual al atletismo: el conjunto impide al cuerpo funcionar como capital. Faltan criterios uniformes de belleza, legitimaciones de salud, jerarquizaciones precisas de la vestimenta, creencia en la reflexividad humana para moldear a fondo la apariencia.

La unificación de la belleza, la legitimación sanitaria de la misma, con sus efectos en la ropa, permitirán valorar una constitución física y encarnar las diferencias sociales. Vemos uno de los enigmas por los cuales el capital erótico institucionalizado ha sido débil. Ya en el mundo clásico se le cuestionaba severamente por sus efectos deletéreos para la vida en común - había una crítica política del capital erótico. Por otra parte, el cuerpo no se consideraba susceptible de modificación.

\subsection{La composición orgánica del capital cultural y el cuerpo}

Jean-Claude Passeron (1982, p. 573) detectó una composición orgánica del capital cultural, a imitación del capital económico en Marx (relación entre la masa de capital invertida en medios de producción y la invertida en fuerza de trabajo). Dicha composición variaría históricamente tanto en sus componentes como en el peso que se atribuye a cada uno de ellos. La analogía servía a Passeron para interpretar un efecto de la inflación de diplomas: cada vez eran más importantes los recursos no monetarios para activarlos y menos el capital propiamente escolar. La analogía plantea problemas: no es lo mismo heredar los medios de producción incluidos en la composición orgánica del capital económico, que heredar el capital cultural. Incorporar el capital cultural familiar exige esfuerzos de interiorización muy superiores a los de una herencia económica. (PASSERON, 2007, p. 13)

La idea, sin embargo, no es inútil. En el mundo griego clásico, los recursos corporales no entraban dentro de los culturales, o al menos muchos obstáculos se oponían. En nuestro caso, acudiendo a una categoría de La reproduction, un nuevo arbitrario cultural permite legitimarlo dentro del capital cultural. Los conflictos no han desaparecido, pero la contestación parece menos masiva que en Grecia. Un libro como el de Hakim, que promueve la utilización consciente del capital erótico, hubiera sido imposible al margen de ese nuevo arbitrario.

La tesis del arbitrario cultural resulta central en la crítica de la violencia simbólica. Creo que se pueden discernir dos articulaciones de tal tesis. En sentido general, cualquier recorte pedagógico (por ejemplo, enseñar matemáticas y no 
atletismo) implica una selección de lo que se enseña y de cómo enseñarlo. Pero no todo es igual de arbitrario en la arbitrariedad cultural. Hoy, por ejemplo, estimamos saludables los músculos y podemos entrenarlos, gracias a lo que, a diferencia de los autores recogidos en el corpus hipocrático, conocemos acerca de la circulación de la sangre. Promover el cultivo del cuerpo resulta menos arbitrario de lo que sería si creyésemos en el paradigma hipocrático. Cuanto menos dependiente de principios lógicos, los contenidos de un arbitrario cultural contribuyen más a la violencia simbólica. Cualquier acción pedagógica se sitúa entre la fuerza y la razón puras, acercándose más a una o a otra. En este segundo sentido, la enseńanza transmite arbitrarios culturales, pero dentro de estos existen grados. (BOURDIEU; PASSERON, 1970, p. 24) Louis Althusser (1995, p. 77-78), por su parte, no negaba que junto a la ideología dominante, la escuela transmitía elementos de cultura científica y literaria. Lo fundamental, pese a todo, es la sumisión porque, incluso cuando se conocen resultados científicos, el sistema de enseñanza oblitera lo propio de la ciencia real: la capacidad de plantear problemas.

Cada arbitrario cultural delimita los componentes, y el peso de estos, dentro de la composición orgánica del capital. Nuestro tiempo, a diferencia del griego clásico, promueve un cuerpo disponible pedagógicamente. En torno al cual se configuran dos prácticas: una, la de la belleza, junto a ella, la de la salud. La legitimidad de ambas no es idéntica: obviamente el arbitrario cultural de la belleza se combate con mayor denuedo. No en vano, cuando se pretende contestar el discurso de salud se le acusa de inspirarse, sin decirlo, en considerandos estéticos.

Respecto de la belleza, Georges Vigarello (2004, p. 37, 81) describe, ya en el siglo XVI, rasgos de una fuerte encarnación de las diferencias sociales: gordo y esbelto se oponen como pobre y rico. Poco a poco, el siglo XVII extiende regímenes de adelgazamiento y el XVIII los cosméticos. Un grupo de expertos en belleza (peluquería, cosmética) pugnan por la definición del cuerpo legítimo que, ya entonces, resulta susceptible de administración pedagógica: el artificio y la belleza se elogian y se pretenden al alcance de los interesados. (VIGARELLO, 2004, p. 119-141) Tras la revolución, los nobles ansían reconstruir corporalmente las jerarquías sociales y la encarnación de la diferencia social se ha convertido en objetivo social y política. La mujer parisina se erige como modelo: bella, ligera, activa, se opone a la provinciana tosca. Durante el siglo XX, las básculas, los consejos de belleza y la estigmatización médica de la gordura le darán amplitud social al objetivo de encarnación. El cuerpo es controlable y, quienes no lo hacen, revelan desidia. (VIGARELLO, 2004, p. 216-217) La belleza, según Vigarello, conoce un proceso de individualización (los seres humanos no reflejan en sí el orden cósmico, sino su propio esfuerzo), de análisis de cada vez más partes del cuerpo y de recombinación permanente de los códigos de distinción. Porque ya en el XIX, nos aclara el autor, menguaban las críticas morales a la belleza: el cuerpo estaba disponible, el trabajo sobre la vestimenta se había complejizado y la identidad de clase se 
reivindicaba por la apariencia. Belleza interior y belleza exterior comunicaban íntimamente: en la nueva composición orgánica del capital, el ligado al cuerpo tiene una legitimidad desconocida en el mundo clásico.

Pero la red de expertos vinculados con la belleza nunca se impondría sin alianza con los vinculados con la salud. De hecho, la coquetería fue históricamente estigmatizada: por la crítica masculina, por la severidad religiosa, por moralismos variados. Oponerse a los preceptos de salud resulta muy difícil. Representan la parte "lógica" dentro del arbitrario cultural ligado a la belleza. La medicina, promoviendo la reflexividad corporal y estigmatizando ciertas morfologías, puede imponer un arbitrario estético. Si la belleza se ampara en la salud, el discurso se acoraza contra la crítica.

Centrémonos en esta cuestión para comprender la complejidad de la alianza entre las prácticas de salud y los modelos corporales legítimos. La idea de un cuerpo pedagógicamente disponible ha sido cuestionada respecto de las dietas de adelgazamiento, uno de los componentes esenciales de la belleza contemporánea. Las dietas, a menudo, resultan fallidas y las tendencias a ganar y perder peso son indiscutiblemente más nocivas que el sobrepeso y la obesidad. Además los beneficios médicos de la pérdida de peso se encuentran lejos de estar probados. Por tanto, desde tales perspectivas, la estigmatización médica de la gordura resulta, siempre desde el punto de vista de la salud, arbitraria. Como en la Grecia hipocrática, muchos especialistas cuestionan la posibilidad de acometer una batalla contra la biología. (LYONS, 2009) Los arquetipos de sobrepeso y obesidad proceden de estereotipos nacidos en las obsesiones de clase media occidental. Tras ellos subyace un intento de encarnar la desigualdad social: en Estados Unidos los gordos (pobres, afroamericanos y latinos) denotarían, con su complexión, sus fallas morales. (OLIVER, 2006, p. 5-11)

Introducir el capital corporal en el cultural tiene, comparado con la Antigüedad, mayores posibilidades: los avances técnicos permiten planificar la modificación del cuerpo. Sin embargo, las dietas fallidas anuncian que el cuerpo resiste a los manejos. Los efectos nefastos de la pérdida de peso producida por las dietas confirman la pertinencia de la categoría de "arbitrario cultural", forjada en La reproduction, para describir la legitimación de la belleza por la salud. La encarnación con la que sueña la clase media tiene fobia a la grasa. Los resultados científicos sobre la obesidad y el sobrepeso discuten, a menudo, las bases clínicas de semejante objetivo.

Quien desee institucionalizar la adquisición de capital erótico debería, a no ser que se olvide de la delgadez (valorizada desde hace siglos en nuestra cultura), cubrirse el flanco ante tales críticas: ¿propone el aprendizaje de algo imposible (porque el cuerpo resiste a la manipulación y a la reflexividad) y dañino? Por muy presente que se encuentre la delgadez en la contemporánea composición orgánica 
del capital cultural, ${ }^{5}$ desde sectores del ámbito científico, en las ciencias sociales y de salud, cuestionan su legitimidad. Asistimos entonces al conflicto entre dos estados del capital cultural: uno (el del valor de la delgadez), implícito y con influencia central entre las mujeres, otro institucionalizado (en el discurso sobre salud) donde existe una lucha tensa por definir qué resulta saludable y qué no. Nos encontramos muy lejos de los griegos, pero no en todo: sobre la solidez del cuerpo y sobre la idoneidad de su cultivo aún tenemos polémicas emparentadas.

\section{Parte}

\section{Desigualdades culturales, desigualdades corporales}

\subsection{No mirar desde la cúspide las desigualdades corporales}

Les Héritiers caracterizó tres formas de desigualdad escolar: eliminación directa de las clases populares, relegación a las ramas menos valiosas del sistema educativo o el estancamiento, fruto del retraso en los estudios o la repetición. (BOURDIEU Y PASSERON, 2003, p. 14-15) De ese modo, Bourdieu y Passeron constataban las diferencias sociales contemplando el sistema educativo desde su cúspide. Las clases populares acumulaban las probabilidades mayores de eliminación, relegación o retraso. El sistema de enseñanza era un juego en el que no se admitían las diferencias de clase. Pese a lo cual, estas jugaban un papel de primer orden en la distribución escolar de los sujetos.

Este modelo tuvo dos críticas. La primera, de inspiración althusseriana, la realizaron Baudelot y Establet (1975, p. 276-279). Bajo este análisis, sostenían los dos sociólogos, subyace la creencia de que la escuela es una realidad única, una suerte de pirámide que, como la pirámide social, podríamos jerarquizar desde la cúspide, midiendo carencias. Baudelot y Establet (1975, p. 151-154) defendían la existencia de dos redes escolares: una primaria-profesional y otra secundariasuperior, la primera dedicada a la clase trabajadora y la segunda destinada a los vástagos de las clases medias y superiores. No nos interesa discutir la teoría de las dos redes de Baudelot y Establet. Lo interesante es que las redes constituyen una manera sociológica de pensar las distintas formas de cultura escolar, exigiendo una precaución: no medir la cultura escolar dominada según criterios de la dominante, ya que ni sus contenidos ni sus prácticas son idénticos. Cuando obramos así, en los de abajo solo sorprendemos defectos respecto de los de arriba.

Al observar el aparato escolar desde la cima de una de sus redes, es decir, al adoptar la perspectiva de la burguesía sobre el aparato escolar, no pueden ver [Bourdieu y Passeron] en las clases 
populares más que a los portadores de desventajas culturales. (BAUDELOT; ESTABLET, 1975, p. 279)

La segunda crítica la produjo el propio Passeron, ya en alianza con Claude Grignon. Ambos desarrollan, sin referirse a ella, una crítica semejante a la de los sociólogos althusserianos. Indudablemente, dentro de una reflexión sobre las culturas populares de enorme alcance. Reconstruiré alguno de sus pasos. En un momento de este libro en diálogo, Passeron se interroga sobre la afinidad electiva entre los métodos de producción de datos y los paradigmas de dominación cultural. El cuestionario tiende a registrar el mundo según los haberes de las clases dominantes: a partir de estos, se registra cuanto falta a las clases populares. Podríamos imaginar que los dominados disfrutan de privilegios de los que carecen los dominantes e incluirlos en el cuestionario. Pero es raro que un sociólogo conozca la cultura dominada y pueda inventariar sus recursos, construyendo una batería de interrogaciones que permita determinar su carencia entre los privilegiados. Yendo hacia las prácticas corporales, los gordos, cuando no viven bajo la culpabilidad, experimentan placeres que las restricciones no procuran. El estudio de los trastornos alimentarios, que no padecen exclusivamente las clases dominantes, podría ofrecer un catálogo de todo el sufrimiento comportado por la persecución del cuerpo legítimo. (MORENO PESTANAA, 2010b) Sin embargo, solemos considerar la gordura desde el prisma de quienes la denigran culturalmente y la discriminan social y económicamente; la delgadez y el cuerpo legítimo, desde el prisma de quienes la ensalzan. Existen otras miradas posibles que arrojarían balances distintos.

La metodología etnográfica puede recoger, de entre los dominados, recursos de los que carecen los dominantes. En ese sentido, sortea la tendencia legitimista de la investigación por cuestionario. El peligro se encuentra en otro lugar. Aislando las culturas dominadas, se obvia la dominación social, como si existiese una discutible sordera, más o menos completa, de las culturas populares respecto de las legítimas. (PASSERON, GRIGNON, 1989, p. 58-59)

Las reflexiones de Passeron siguen inspirando buenas preguntas sociológicas. La tendencia de la etnografía a construir las culturas desde la autonomía, y a ignorar su vinculación con la dominación, se vislumbra en ciertos razonamientos del segundo capítulo del trabajo de Debra L Gimlin (2002). El libro contiene una hermosa etnografía de un salón de belleza, una clase de aerobic, una clínica de cirugía estética y un baile de una asociación de defensa de personas gordas. Analizando la clase de aerobic constata la enorme sensación de confianza alcanzada por las participantes. ¿Cuál es la razón? El cumplimiento de una norma de comportamiento que estriba en regular la alimentación y continuar con el deporte. En ese momento, seńala la autora, pueden olvidarse del cuerpo y dedicarse a otras actividades. ¿Tiene que ver ello con la dominación? ¿No asistimos a una enorme 
emancipación de las mujeres?, se pregunta la autora. Las críticas del discurso de la belleza ignoran el empoderamiento femenino, las capacidades que las mujeres pueden desarrollar precisamente por atenerse a la norma dominante.

Todo depende de la escala de análisis, podría responderse. De centrarnos en la experiencia individual de las afectadas, evidentemente sienten una enorme liberación. Ahora bien, el precio de la misma ha sido incorporar las exigencias de legitimidad de las normas de género. Éstas obligan a las mujeres a asumir, para sentirse en paz consigo mismas, un mínimo común denominador corporal. Desde ese punto de vista, solo sujetándose a una práctica de dominación de género adquieren libertad los individuos. Para ser sujeto, necesitamos sujetarnos a ciertos sistemas de reglas. El criterio sociológico de emancipación no es idéntico al criterio político: con el primero alcanzamos movilidad social dentro del marco hegemónico, con el segundo lo cuestionamos y lo transformamos. (GIL CALVO, 2000, p. 238-240)

El efecto de la visión legitimista del cuerpo ronda la investigación por cuestionario, incluso en las más armadas de reflexividad teórica. Dieter Vandebroeck (2013, p. 174-175), en una importante contribución a la sociología de las desigualdades corporales, muestra cómo en la cúspide social se encuentran los cuerpos más atractivos. Así, en una escala del uno al diez, la satisfacción con el propio peso crece entre las mujeres de clases dominantes $(6,3)$, mientras que en las de clase obrera solo es un 5,8; un $36 \%$ de las segundas se considera atractiva frente a un $52 \%$ de las primeras. Un $16 \%$ de las dominantes se consideran con sobrepeso u obesas lo que asciende a un $46 \%$ de las dominadas.

Vandebroeck constata, con toda justicia, la encarnación de las diferencias sociales en las corporales. Existe una desigual probabilidad de alcanzar los cuerpos más admirados y, coherente con ello, la sensación de menosprecio tienden a avanzar conforme descendemos socialmente. Pero, entroncando con las críticas al modelo de dominación formulado en Les héritiers, podemos formular las siguientes preguntas: las personas que, dentro de cada entorno, desentonan con los porcentajes dominantes, ¿ansían constantemente subsanar sus carencias? ¿Pueden desconectarse de las exigencias del cuerpo legítimo en algunos momentos de su experiencia? Cuando el capital cultural sirve, por ejemplo, para denunciar el arbitrario del capital estético, ¿permite esto recuperar la propia dignidad? ¿Significa que, como en la fábula de la zorra y las uvas, se protege de cuanto no tiene? Si así fuera, hablaríamos de lo que Passeron denomina un comportamiento ambivalente, que aparenta recusar la dominación cuando en el fondo acepta sus dictámenes. ¿Significa, por el contrario, que en ciertos espacios no se siente interpelado y puede liberarse de la sensación de dependencia? Tal es el efecto de la alternancia. (PASSERON; GRIGNON, 1989, p. 106-109) O, simplemente, significa el enfrentamiento entre dos fuerzas que se impugnan la una a la otra. Así, 
cuando desde un cierto tipo de capital cultural se cuestiona la arbitrariedad del capital erótico - y por tanto su aceptación como capital cultural válido.

La Reproduction daba otra respuesta a este problema que nos animaba a no pensar en la sociedad como en un mercado unificado, contemplado desde la elite. En la sociedad coexisten diferentes acciones pedagógicas que no siempre encuentran un contexto donde expresarse. En una sociedad no todo funciona según los sanciones de las clases dominantes: porque éstas se encuentran internamente divididas $^{6}$ y porque ninguna sociedad constituye algo unificado y dominado por un exclusivo principio. Recuerdan, para ello, la relación entre los diversos modos de producción en una formación social. La agricultura o el artesanado tradicionales tienen que valorizar sus productos en el mercado capitalista. Las formas de organización y retribución de los trabajos tradicionales funcionan, sin embargo, con otra lógica. (BOURDIEU; PASSERON, 1970, p. 44) Aquellos que se desvían de los cuerpos legítimos pueden medirse con otros criterios, olvidar la lógica dominante e incluso construirse regidos por otros criterios de valor.

El cuarto capítulo de la etnografía de Debra L. Gimlin (2002) en los bailes de la National Association to Advance Fat Acceptance ofrece un ejemplo sociológico. En ella podemos contemplar la dificultad de construir cierta autonomía respecto de la cultura dominante y la fragilidad de la misma, siempre amenazada por la reimposición de los criterios de valor hegemónicos. Antes de asistir al baile, entre personas gordas, ninguna de las participantes se habían considerado atractiva, precisamente porque su apariencia les resultaba absolutamente inaceptable: el cuerpo atravesaba territorios hostiles donde los insultos se desencadenaban fácilmente. En el baile, sin embargo, Gimlin las contempló llamando la atención sobre sus propios cuerpos. Creaban lo que Pierre Bourdieu (2001, p. 140-143) llamó un mercado franco (en el mismo sentido en que hablamos de un puerto franco) respecto de la norma dominante, como los existentes en los bares de clase trabajadora. En ellos funciona un argot descalificado en los mercados legítimos. Bourdieu advierte que esos mercados solo son libres en apariencia, si entendemos por libres expresión de hábitos relajados. El grupo de pares vigila constantemente cualquier ejercicio de distinción penalizando a quienes introducen la norma dominante, por ejemplo, el lenguaje o los temas escolarmente prestigiosos.

El baile, como el mercado del argot popular, aparcaba la norma dominante, pero muy frágilmente. Gimlin constató que todas las participantes deseaban perder peso y, cuando lo hacían, despreciaban el entorno protegido, ridiculizando a los hombres que prefieren mujeres gordas. De hecho, la propia antropóloga, delgada, introducía inquietud. Era un espacio costosamente resguardado y que exigía homogeneidad para entrar en él. Pero, sin duda, era un mercado dominado por la norma que deseaba excluir. Cuando esta aparecía, los equilibrios se rompen. 


\subsection{La experiencia de la interpelación}

Perseguir o no el capital cultural depende, se nos decía en Les Héritiers (BOURDIEU; PASSERON, 2003, p. 39), de la relación entre las esperanzas objetivas de una categoría social y sus esperanzas subjetivas. Gracias a la colaboración de Alain Darbel, Bourdieu y Passeron contaron con un algoritmo estadístico que les permitió calcular las oportunidades, para cada categoría de estudiantes, de acceder a la Universidad y a las diferentes carreras. Pero, evidentemente, los individuos no son estadísticos de profesión. Se impone, pues, para ofrecer una versión realista de su experiencia social, perseguir "[...] los índices concretos de los futuros probables o improbables que pueden ser conocidos u observados por los sujetos en su entorno próximo [...]". (PASSERON, 2007, p. 12)

La inversión en un juego cultural, o corporal, depende de la atracción que despierta, atracción repartida siempre de manera socialmente significativa. Por un lado, necesita conocerse si el arbitrario cultural-corporal se transmitió tempranamente. Dicha transmisión temprana puede encontrarse (o no) en sintonía con la socialmente dominante en un contexto o en otro. El juego del capital cultural, y del corporal, se transmite con la articulación de tres propiedades: la trayectoria del individuo, los rasgos de ese arbitrario cultural y su papel, dominante o no, en una formación social determinada. (BOURDIEU; PASSERON, 1970, p. 45) El Viejo Oligarca podía exigir la visibilidad de la desigualdad en la ropa de los atenienses: la formación social en la que se desenvolvía contravenía, por razones diversas, semejante demanda. Una persona puede imitar el arbitrario corporal dominante: las exigencias de éste pueden contrariar tanto sus gustos que, finalmente, renuncia a perseguirlo. La trabajadora de una tienda de moda, pese a su exiguo salario, se vuelca en el cuidado de su figura, aunque éste contraríe los gustos alimentarios adquiridos en su familia. El valor del modelo corporal legítimo la pone en contacto con una clientela distinguida. En la interacción con ella, aconsejando tendencias y actuando como una experta, ocupa una situación de privilegio profesional. Ésta confirma el valor social de su actividad profesional y refuerza su compromiso corporal. Otras posibilidades se presentan que no van a desarrollarse: la clave es retener el juego complejo entre la práctica que se defiende, su lugar en las jerarquías sociales y culturales y su mayor o menor receptividad por la cultura incorporada por los individuos.

El modelo, sin embargo, se piensa como dinámica entre diversos subsistemas culturales. Falta describir cómo lo experimenta el individuo. Louis Althusser ofrece una preciosa ayuda. El filósofo intentó captar la relación entre esperanzas objetivas y subjetivas describiendo la interpelación ideológica. La interpelación se organiza según cuatro dimensiones. Con la primera, los individuos se sienten llamados a volcarse en una actividad, en una práctica: moral, educativa, corporal. Althusser habla de la "interpelación de los individuos en sujetos": sujetos de una 
red de prácticas y de identificaciones, a la vez agentes en ellas, a la vez dominados por ellas. En la segunda dimensión, el individuo se consagra a una norma social establecida, que se convierte en el espejo desde el que juzga su realidad empírica. ${ }^{7}$ Es, nos dice con jerga lacaniana, la sujeción al Sujeto con mayúsculas, cuyos veredictos imaginarios mantienen el sacrificio y refuerzan el compromiso de los individuos empíricos. La tercera dimensión, algo redundante con la segunda, exige reconocer el juego y a los contendientes en el mismo, incorporar baremos de imitación y diferenciación. Configurar por tanto, un mundo de próximos significativo, que resultan pertinentes para medirse con ellos y según criterios acreditadas: puede ser el Índice de Masa Corporal, la posesión de un título de peluquería, la información respecto a la moda en diferentes franjas de edad, periodos estacionales o mercados específicos (conocer qué se lleva en Tokio o en Rabat no tiene el mismo valor simbólico). La cuarta dimensión es “[...] la garantía absoluta de que todo está bien así y que, con la condición de que los sujetos reconozcan lo que son y se conduzcan en consecuencia, todo irá bien [...]”. (ALTHUSSER, 1995, p. 310)

Las tres dimensiones de la interpelación (la segunda y la tercera pueden fundirse) constituyen indicadores de su eficacia y, por ende, guías para comprender su fracaso. La lejanía social de una práctica puede impedir que se configuren esperanzas subjetivas. Los fracasos corporales repetidos por adoptar rituales de adelgazamiento testimonian distancia social (y también biológica) respecto de la norma hegemónica. El individuo deja de considerarse capacitado para ser sujeto de una práctica que le incapacita profundamente. La segunda y la tercera dimensión (fusionadas) permiten también describir defecciones en las carreras: las propiedades de aquellos que te reconocen como sujeto pueden impedir asumir su juego. Las reglas de éste, las mortificaciones que implica, los estragos producidos en otras áreas de tu experiencia pueden animarte a abandonar, a considerar que ese reconocimiento ni lo puedes ni lo quieres tener. En fin, la última dimensión describe bien la pérdida radical de afecto por el juego y la norma: por más que se practica no se logra lo que se prometía, la garantía se encuentra falsificada, nada funciona como se esperaba. El futuro ansiado se demuestra una quimera. La norma corporal dominante deja de atrapar al individuo.

\section{Conclusión}

Comparándolo con el capital cultural, se comprenden dos de las peculiaridades del capital erótico. Primera, la dificultad de institucionalizarlo, resultado de menor legitimidad histórica respecto de otras formas de capital cultural. En segundo lugar, se presentaron las formas diversas de conflicto respecto del mismo: el capital erótico, como el cultural, no gobierna automáticamente los anhelos de los individuos. De hecho existen posibilidades de separarse de la imposición. Para 
que el cuerpo funcione como capital debe hacer consenso respecto de la belleza física (y de la posibilidad de alcanzarla), respecto de la jerarquía en el vestuario y tasarse tales elementos como emblemas de una identidad a celebrar.

Si se cuestionan los patrones de belleza (o la posibilidad de alcanzarlos), si el atuendo se embrolla en signos sin significado social o si la apariencia física se rechaza como identidad, parece difícil que se extiendan mercados donde el capital erótico encuentre recompensa. Nuestra sociedad funciona con prototipos de belleza relativamente estables (la delgadez, por ejemplo, es un rasgo promocionado desde hace siglos), con prácticas de combinación del atuendo que cotizan según transmiten mercados simbólicos de élite y con la idea de que en el aspecto se transmiten cualidades morales de los individuos (su cuidado de sí, su autodisciplina). Cabe cuestionar los patrones comunes de belleza (y considerarlos al alcance de muy poca gente, esto es: indisponibles para la mayoría), el valor de los referentes de la alta costura y sus imitadores y transmisores o, sencillamente, el sentido de la apariencia física para encarnar algo que no sea la caprichosa herencia genética - o una ansiosa voluntad por domesticarla que cercena, por las energías que demanda, las potencialidades de un individuo.

En ese momento, el relato del cuerpo dejaría de interpelarnos. Althusser explicaba que la ideología impone reconocer algo desconociendo profundamente su funcionamiento real. En el fracaso, cuando la interpelación se muestra tramposa, el desconocimiento se descascarilla y avanzan briznas de conocimiento. La resistencia comienza a ser posible.

\section{Notas}

1. Texto escrito en el marco del proyecto de I+D FFI2010-15196.

2. Para una visión más amplia de la relación entre Bourdieu, Passeron y Althusser, véase mi introducción al Razonamiento Sociológico. (MORENO PESTAÑA, 2010a) Judith Butler (2001, p. 133), analizando la categoría de interpelación (sobre la que me ocuparé), considera que el habitus de Bourdieu es una "reformulación de la noción althusseriana de la ideología". Dadas las fechas de publicación podría pensarse lo contrario, aunque la cuestión de las prioridades es absurda. Si pensamos en una red de discusión y publicación, la unidad de los temas impone su lógica. Incluso las diferencias planteadas por Baudelot y Establet entraban dentro de la matriz teórica compartida: veremos cómo también se las plantea, por su cuenta, Jean-Claude Passeron.

3. Sobre los ejes de análisis del cuerpo véase Gil Calvo (2000, p. 26).

4. Aristóteles, en la Retórica (1361b), distingue formas de belleza por clases de edad. Efectivamente, atletismo e impacto visual distinguen a los jóvenes, pero no a los maduros (el cuerpo debe producir agrado y temor y ser útil para la guerra) ni a los viejos, a los que basta con carecer de achaques. En el modelo de Aristóteles se impugna una de las claves de los modelos de capital corporal contemporáneo: la juvenilización, la unificación de la belleza por encima de las clases de edad, la creencia de que el patrón corporal se encuentra, para cualquiera que se esfuerce, pedagógicamente a su disposición.

5. La inversión corporal (entre la cual, la persecución de la delgadez) aumenta con el capital cultural femenino como muestran múltiples trabajos estadísticos. Véase Saint-Pol (2010, p. 115-116) y nuestra discusión en Moreno Pestaña y Bruquetas Callejo (2015). Sobre el capital erótico y el reclutamiento de trabajadoras véase Moreno Pestańa (2015). 
Qué nos enseña el capital cultural para pensar el capital erótico

6. Louis Althusser (1995, p. 229), dentro de su modelo, lo dejaba muy claro. Los individuos se encuentran sometidos a exigencias ideológicas familiares, jurídicas, religiosas, morales y escolares que no siempre resultan coherentes. "Sujetarse" a las exigencias de la ideología familiar puede entrar en conflicto con la ideología escolar o moral. La interpelación ideológica, a la que enseguida me referiré, no cementaba sujetos en torno a normas homogéneas y coherentes. Los cementaba en el conflicto.

7. En otra formulación esta segunda dimensión desaparece y su presencia no parece fundamental. (ALTHUSSER, 1995, p. 232)

\section{Referências}

ALTHUSSER, L. Sur la reproduction. Paris: PUF, 1995.

ARISTÓTELES. Retórica. Madrid: Alianza, 2002.

BAUDELOT, C.; ESTABLET, R. La escuela capitalista en Francia. Madrid: Siglo XXI, 1975.

BUTLER, J. Mecanismos psíquicos del poder. Valencia: Cátedra, 2001.

BOURDIEU, P. Les trois états du capital culturel. Actes de la recherche en sciences sociales, v. 30, p. 3-6, 1979.

. Langage et pouvoir symbolique. Paris: Seuil, 2001.

BOURDIEU, P.; PASSERON, J.-C. La reproduction. Éléments pour une théorie du système d'enseignement. Paris : Minuit, 1970.

. Los herederos. Los estudiantes y la cultura. Buenos Aires: Siglo XXI, 2003.

GIL CALVO, E. Medias miradas. Un análisis cultural de la imagen femenina. Barcelona: Anagrama, 2000.

GRIGNON, C.; PASSERON, J.-C. Le savant et le populaire. Misérabilisme et populisme en sociologie et en littérature. París: Gallimard-Seuil, 1989.

HAKIM, C. Capital erótico. El poder de fascinar a los demás. Barcelona: Debate, 2012.

HILL, S. E. Eating to excess. The meaning of gluttony and the fat body in the Ancient World. Santa Barbara: Praeger, 2011.

LYONS, P. Prescription for Harm: Diet Industry Influence, Public Health Policy, and the Obesity Epidemic. In: ROTHBLUM, E; SOLOVAY, S. (Eds.). The Fat Studies Reader. New York: New York University Press, Kindle File, 2009.

MORENO PESTAÑA, J. L. Estudio preliminar. Una filosofía de las ciencias históricas: presentación de la obra de Jean-Claude Passeron. In: PASSERON, J.-C. El razonamiento sociológico. El espacio comparativo de las pruebas históricas. Madrid: Siglo XXI, 2010a.

. Moral corporal, trastornos alimentarios y clase social. Madrid: CIS, $2010 \mathrm{~b}$.

. Le marché préfère les minces. La Vie des idées, 4 février 2015. Disponible en: $<$ http://www.laviedesidees.fr/Le-marche-prefere-les-minces.html>. [ISSN: 2105-3030]. 
MORENO PESTAÑA, J. L.; BRUQUETAS CALLEJO, C. Sobre el capital erótico como capital cultural. Revista Internacional de Sociología. [en prensa, 2015].

OLIVER, J. E. Fat politics. The real story behind America's obesity epidemic. Nueva York: Oxford University Press, 2006.

OSBORNE, R. The history written on the classical greek body. Cambridge: Cambridge University Press, 2011.

PASSERON, J.-C. L'inflation des diplômes. Remarques sur l'usage de quelques concepts analogiques en sociologie. Revue française de sociologie, n. XXIII, p. 551-584, 1982.

. Que reste t'-i-l des Héritiers et de La Reproduction (1964-1971) aujourd'hui? Questions, méthodes, concepts et réception d'une sociologie de l'éducation. Sociological Research Online, v. 12, n. 6, p. 13, 2007. Disponible en: <http://www.socresonline.org. uk/12/6/13.html>. Acceso en 26 de julio de 2014. [doi: 10.5153/sro.1452].

PLATÓN. La República. Madrid: Alianza, 2008.

ROMILLY, J. Los grandes sofistas en la Atenas de Pericles. Una enseñanza nueva que desarrolló el arte de razonar. Barcelona: Seix Barral, 1997.

SAINT-POL, T. Le corps désirable. Hommes et femmes face à leur poids. Paris: PUF, 2010.

VANDEBROECK, D. Harnessing the flesh. Social class and reflexive embodiment. Tesis (Doctoral en Sociología). 2013. Universidad Libre de Bruselas. 2013.

VIGARELLO, G. Histoire de la beauté. Le corps et l'art d'embellir de la renaissance à nos jours. Paris: Seuil, 2004.

Recebido em 29 de agosto de 2014.

Aprovado em 13 de fevereiro de 2015. 